\title{
Spatial Brightness, Horizontal Illuminance and Mean Room Surface Exitance in a Lighting Booth
}

James Duff

Technological University Dublin, james.duff@arup.com

Kevin Kelly

Technological University Dublin, kevin.kelly@tudublin.ie

C. Cuttle

Havelock North, New Zealand.

Follow this and additional works at: https://arrow.tudublin.ie/engscheleart2

Part of the Electrical and Electronics Commons

\section{Recommended Citation}

Duff, J., Kelly, K. \& Cuttle, C. (2015) Spatial Brightness, Horizontal Illuminance and Mean Room Surface Exitance in a Lighting Booth, Lighting Research and Technology, 49(1) · July 2015 doi:10.1177/

1477153515597733

This Article is brought to you for free and open access by the School of Electrical and Electronic Engineering at ARROW@TU Dublin. It has been accepted for inclusion in Articles by an authorized administrator of ARROW@TU Dublin. For more information, please contact arrow.admin@tudublin.ie, aisling.coyne@tudublin.ie, gerard.connolly@tudublin.ie.

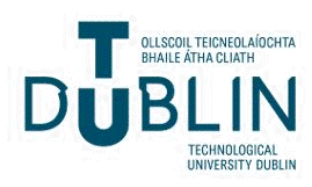




\title{
Spatial brightness, horizontal illuminance and mean room surface exitance in a lighting booth
}

\section{JT Duff BSc, K Kelly $\mathrm{PhD}^{\mathrm{b}}$ and C Cuttle $\mathrm{MA}^{\mathrm{c}}$}

\author{
${ }^{a}$ Arup Lighting and Dublin Institute of Technology, Dublin, Ireland \\ ${ }^{\mathrm{b}}$ School of Electrical Engineering, Dublin Institute of Technology, Dublin, Ireland. \\ ${ }^{\mathrm{c}}$ Havelock North, New Zealand.
}

Short title: Spatial brightness, horizontal illuminance and MRSE

Received 22 April 2015; Revised 10 June 2015; Accepted

This paper presents a pilot study that has investigated the suitability of mean room surface exitance as a predictor of spatial brightness and compared these results with how horizontal illuminance predicts spatial brightness under the same conditions. The experiment took a group of 26 participants and, using a scaled booth, exposed each participant to three levels of mean room surface exitance, each delivered with three different light distributions and three different surface reflectances, resulting in a total of 27 light scenes. Results demonstrated that, under the range of conditions to which participants were exposed, a systematic relationship existed between mean room surface exitance and spatial brightness, but not between horizontal illuminance and spatial brightness.

Address for Correspondence: James Duff, Ove Arup and Partners Ltd, 50 Ringsend Road, Dublin 4, Ireland.

E-mail: james.duff@arup.com 


\section{Introduction}

In recent years, indoor lighting standards and guidance documents have changed to allow designers the option to select the orientation of the working plane within a space, which may, or may not be, the horizontal plane. In addition, new metrics such as mean cylindrical illuminance, a modelling index and minimum quantities of illuminance on major room surfaces have been added. ${ }^{1-2}$ Whilst these have been formally introduced into standards and guidance, for those working within the lighting industry, it can be observed that the most prominent lighting metric in practice remains the quantity of illuminance on the horizontal working plane. This observation is supported by Boyce who states; "Despite the use of task plane rather than working plane in recent recommendations and the fulminating of various eminent personages, the fact is the horizontal working plane is still the plane of choice for simple lighting calculations". 3

Over the past decade, Cuttle has been the prime advocate for reforming indoor lighting standards from their current state, to consider an alternative approach that he believes better relates to what we see. ${ }^{4,5,6,7,8}$ Cuttle has suggested that mean room surface exitance (MRSE),5 being the measure of overall density of reflected (excluding direct) luminous flux within a space, is a metric that may correlate with the perceived brightness of a space, or in other words, the spatial brightness. Spatial brightness is a term that relates to the perceived quantity of light within a space, or the light that is influencing the appearance of a space rather than illuminating the tasks. Fotios et al provide a good review ${ }^{9}$ and for reference, 
spatial brightness has previously been referred to as building lighting, ${ }^{10}$ room brightness ${ }^{11}$ and in some more recent studies, scene brightness. ${ }^{12,13}$

Cuttle proposes MRSE with the intention that it would be a proxy for the quantity of light arriving at the eye, which could also be represented by the indirect illuminance on a vertical plane at eye level. Many past studies have investigated the influence of spectral power distribution on spatial brightness, $9,14,15,16,17,18,19,20,21,22,23,24,25$ whilst others have examined the influence of light on a horizontal or vertical plane ${ }^{26}$ and within a defined field of view. ${ }^{27,28}$ Rea et al found better correlations with brightness between illuminance measured on a vertical plane than with that measured on a horizontal plane. ${ }^{26}$ In two separate studies, Loe et al found strong correlations between assessments of brightness and the illumination of a horisontal band $40^{\circ}$ wide..$^{27,28}$

Cuttle’s ideas have generally been well received ${ }^{29,30,31,32,33,34}$ and Boyce ${ }^{3}$ even offers the procedure as one of three possible ways in which the gap between indifferent quality lighting and good quality lighting might be bridged in the future. However, before Cuttle's ideas can be considered for implementation, the relationship between MRSE and spatial brightness must be better understood. This paper investigates the relationship between MRSE and spatial brightness, and also compares the relative merits of MRSE and horizontal illuminance $\left(E_{h}\right)$ as suitable predictors of spatial brightness. Whilst the spectral power distribution of a light source is very relevant to perceived spatial brightness, this study deals only with how the level of MRSE, the associated spatial distribution of the light and the space surface properties influence the perception of spatial brightness.

\section{Method}


A lighting booth was constructed from MDF and sealed for light tightness using silicone caulk (Figures 1 and 2). The booth was $860 \mathrm{~mm}$ high, $1500 \mathrm{~mm}$ long and $850 \mathrm{~mm}$ deep and contained multiple hatches spaced out in a regular grid on all sides of the booth. The smaller hatches were used solely for measurement. Two large hatches, one on each long elevation of the booth, facilitated viewing points, with volunteer participants pressing their faces against this to view the booth interior. The booth sat $750 \mathrm{~mm}$ above finish floor level on in-built legs. Luminance values were recorded through each of the measuring hatches and converted to MRSE using equations 1 and 2. Luminance values were recorded using an independently calibrated Konica Minolta LS-110. Reflectance values were calculated using luminance and illuminance measurements. Prior to beginning the each experiment, all lamps were run at full output for a sufficient length of time so that their output stabilised. This was verified with spot measurements taken at the start and end of each light scene.

For each surface within the booth, the mean exitance $\left(\mathrm{M}_{\mathrm{S}}\right)$ of that surface is given by the product of the mean recorded luminance $\left(\mathrm{L}_{\mathrm{S}}\right)$ and pi:

$$
M_{S}=L_{S} \pi
$$

The MRSE is then given by the sum of the product of the mean exitance $\left(M_{S}\right)$ and area $\left(A_{S}\right)$ for all surfaces, divided by the total room surface area:

$$
M R S E=\frac{\sum M_{S} A_{S}}{\sum A_{S}}
$$

Lighting in the booth was provided by pulse width modulation (PWM) dimmable 300 mm T5 fluorescent lamps, with two of each located inside custom aluminium housings. The lamps had a correlated colour temperature of $4000 \mathrm{~K}$ and a colour rendering index of 80 . Lamps were circuited, grouped (SC-1, SC-2, SC-3 in Figure 2) and dimmed together to 
produce uplight and downlight components. Light scenes were programmed using a DSI interface and a scene set panel.

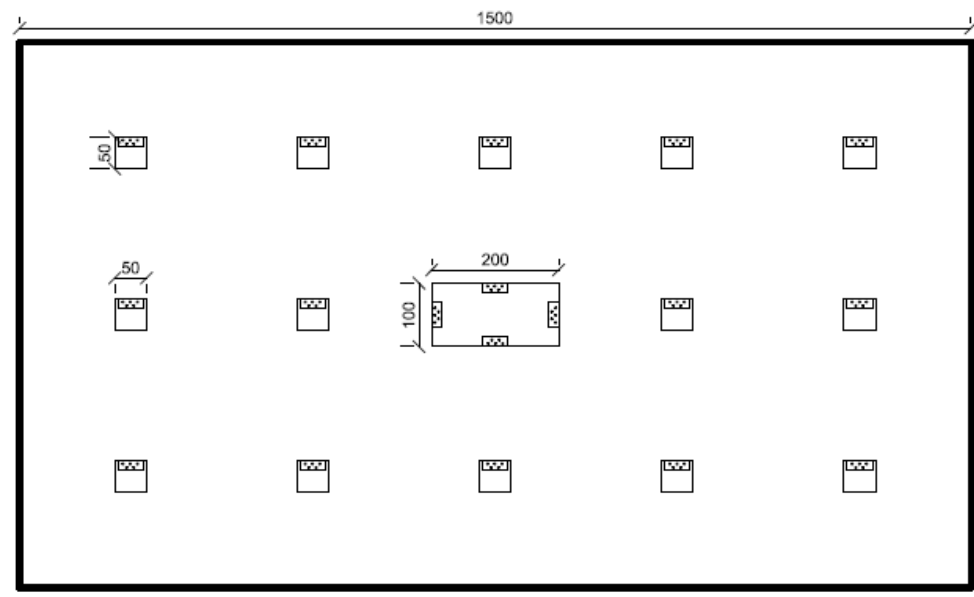

Figure 1. Front elevation of the lighting booth. Note the smaller measuring hatches and the larger central hatch for viewing. Measuring hatches, at similar spacing, were used on all sides of the booth, including the top and bottom surfaces.
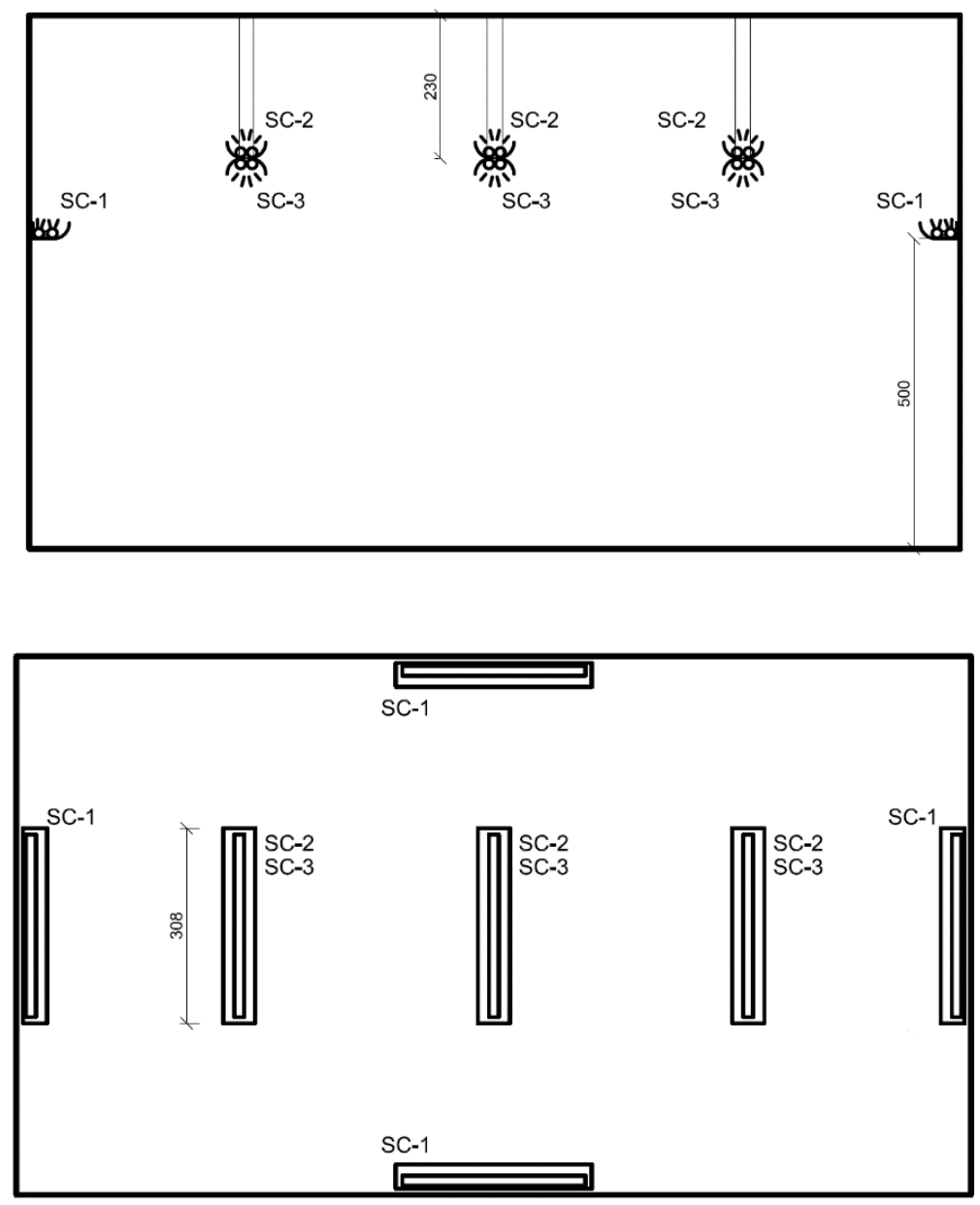

Figure 2. Elevation and plan sections of the lighting booth. Note the position of lamps and the switching circuits as described in Section 2. 
The study examined the subjective response to the spatial brightness perception of 26 participants. Participants were between the ages of 18 and 25 years (mean=20.8 years, standard deviation=2.3 years) with no participant using corrective eyeware. In each experiment, participants viewed a range of light scenes. The experiment used groups of two participants and each participant completed three separate sittings. During each sitting, participants were exposed to nine different light scenes at varying levels of MRSE, with the corresponding level of $\mathrm{E}_{\mathrm{h}}$ at booth floor level also recorded. Three levels of MRSE were set up; 25, 50 and $100 \mathrm{~lm} / \mathrm{m}^{2}$, along with three methods to achieve the distributions of each, these being indirect, direct and mixed. Indirect scenes were a combination of SC-1 and SC-2, direct scenes were solely SC-3 and the mixed scenes were a combination of all three switching circuits. The reflectance on the internal surfaces of the booth and within the interior of the experimental space were also varied to broadly represent light, medium and dark surface properties. Together, these combinations produced a total of 27 light scenes. A graphical breakdown of the light scenes is given in Figure 3 and further details about surface reflectances and luminance distributions are given in Table 1.

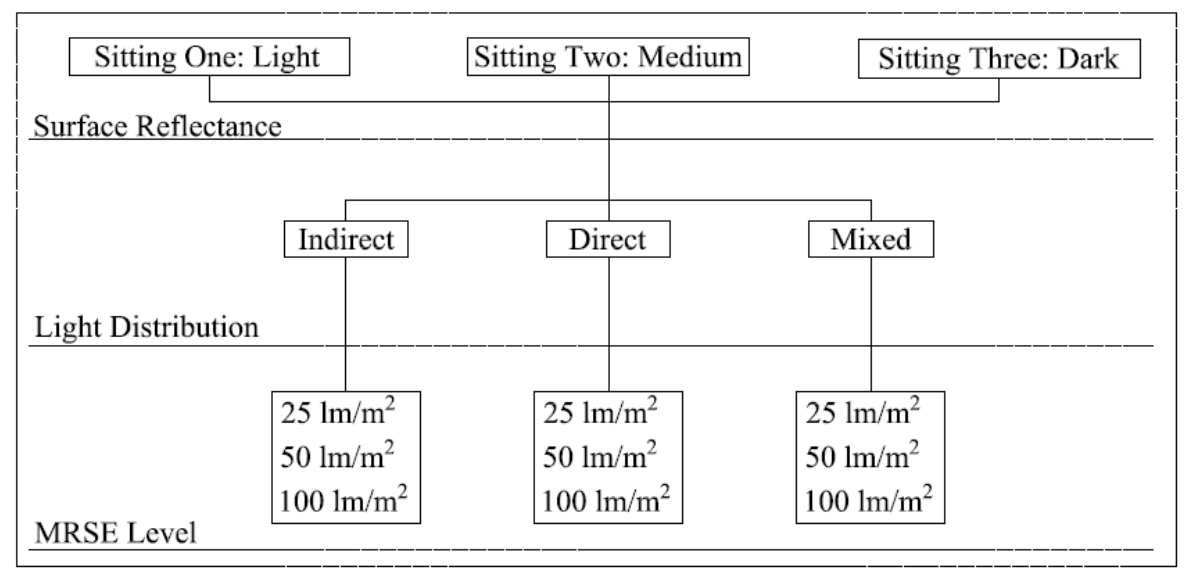

Figure 3. Graphical representation of each light scene programmed. Note that each sitting contained static surface reflectances, but varied levels of MRSE and light distribution. 
The order of exposure to light scenes was randomised and three scenes were repeated to compare participant responses. The numbering of each light scene is given in Table 1 . The repeated scenes were scene 7, scene 14 and scene 21 and were chosen to best include each of the variables; being one scene from each level of MRSE, one scene from each light distribution and one scene from each surface reflectance. Participants were exposed to each scene for two minutes and during each scene, answered one question that examined subjective spatial brightness levels on a seven point semantic differential scale. Question response polarity was varied at random to prevent directional bias.

Q1. On the scale below, please rate the brightness of the entire booth.

\begin{tabular}{l|l|l|l|l|}
$\begin{array}{l}\text { very } \\
\operatorname{dim}\end{array}$ & $\operatorname{dim}$ & $\begin{array}{l}\text { slightly } \\
\text { dim }\end{array}$ & $\begin{array}{l}\text { neither dim } \\
\text { nor bright }\end{array}$ & $\begin{array}{l}\text { slightly } \\
\text { bright }\end{array}$
\end{tabular} \mid bright $\mid \begin{aligned} & \text { very } \\
& \text { bright }\end{aligned}$

Brightness scales were defined using the definition coined by Vrabel et al ${ }^{35}$; “very bright is represented by the light in an outdoor sports area (when all the floodlights are on) and very dim is the level of an outdoor parking lot at night”. In addition to this, participants were reminded prior to each scene change that they should relate brightness to the entire booth, and not solely to their immediate field of view.

\section{Results}

Values of one to seven were assigned for responses from very dim to very bright, respectively. A full list of the mean spatial brightness response ratings, coupled with the associated standard deviations, for all light scenes is given in Table 1.

\section{Data analysis}

Using parametric statistical tests requires the data to be drawn from a normally distributed sample. Distribution of data was investigated using statistical and graphical methods 
available through SPSS, namely; measures of central tendency, skewness, frequency histogram, kurtosis, box and whisker plots and probability plots. These tests indicated that the data were not normally distributed and as such, non-parametric statistical tests have been applied.

\subsection{Repeated scenes}

Repeated scenes were introduced to ensure that the order of light scene exposure had no impact on subjective assessments. As stated previous, three scenes were repeated without participants knowledge; scene 7, scene 14 and scene 21, with the repeated scene being excluded from the final results. Scores produced from each of these scenes were examined using the Wilcoxon signed-rank test. All three repeated scenes produced no statistically significant differences between participants' first response and their second (scene 7, Z = 0.933, $\mathrm{p}=0.351$; scene $14, \mathrm{Z}=-1.155, \mathrm{p}=0.248$ and scene $21, \mathrm{Z}=-1.265, \mathrm{p}=0.206)$. It can thus be concluded that the order of exposure had no significant impact on participants' assessments.

\subsection{Mean room surface exitance and spatial brightness}

Repeated measures analysis of variance (ANOVA) was used to investigate the influence of the different independent variables on spatial brightness assessments. To change the reflectance of the internal surfaces of the booth, they were repainted and as such, it could not be avoided that participants saw each surface reflectance in the same order, producing an associated order effect. For this reason, three separate two by three repeated measures ANOVA's were carried out, with level of MRSE (3) and light distribution (3) as the independent variables.

In sitting one, participants viewed scenes with light surface reflectances as given in Table 1. Mauchly's test of sphericity demonstrated that for these results, sphericity could be assumed for light distribution, $\mathrm{X}^{2}(2)=5.49, \mathrm{p}=0.064$, level of MRSE, $\mathrm{X}^{2}(2)=0.0256, \mathrm{p}=$ 
0.987, and the interaction between level of MRSE and light distribution, $X^{2}(9)=2.682, p=$ 0.976. Within subjects effects then showed that the subjective assessment of spatial brightness was influenced by the level of MRSE, F(2, 50) $=190.112$, $\mathrm{p}<0.001$, and also by light distribution, $\mathrm{F}(2,50)=15.605, \mathrm{p}<0.001$. There was no significant interaction between level of MRSE and light distribution, $\mathrm{F}(4,100)=0.182, \mathrm{p}=0.947$.

Post-hoc paired comparisons, using a Bonferroni correction, were made to examine which pairs of means differed. For light distribution, there was a significant difference between direct and indirect scenes $(\mathrm{p}<0.001)$ and also between direct and mixed $(\mathrm{p}<0.001)$. No statistically significant difference could be found between the mixed and indirect scenes. For level of MRSE, there was a statistically significant difference between each of the pairs of means $(\mathrm{p}<0.001)$. 

In sitting two, participants viewed scenes with medium surface reflectances as given in Table 1. Mauchly's test of sphericity demonstrated that for these results, sphericity could be assumed for light distribution, $\mathrm{X}^{2}(2)=2.314$, $\mathrm{p}=0.314$, and for the interaction between light distribution and level of MRSE, $X^{2}(9)=13.629, p=0.137$, but not for level of MRSE, $X^{2}(2)=12.954, p=0.002$. For level of MRSE, $F$ values are reported using degrees of freedom corrected with the Greenhouse-Geisser factor $(\varepsilon=0.706)$. Within subjects effects showed that subjective assessment of spatial brightness was influenced by level of MRSE, $\mathrm{F}(1.41,35.3)=145.958, \mathrm{p}<0.001$, and also by light distribution, $\mathrm{F}(2,50)=13.474, \mathrm{p}<$ 0.001. There was also a significant interaction between level of MRSE and light distribution, $\mathrm{F}(4,100)=4.698, \mathrm{p}=0.002$

Post-hoc paired comparisons, using a Bonferroni correction, were made to examine which pairs of means differed. For light distribution, there was again a significant difference between direct and indirect scenes $(\mathrm{p}<0.001)$ and also between direct and mixed $(\mathrm{p}<0.001)$, but with no statistically significant difference being concluded between the mixed and indirect scenes. For level of MRSE, there was again a statistically significant difference between each of the pairs of means $(p<0.001)$.

In sitting three, participants viewed scenes with dark surface reflectances as given in Table 1. Mauchly's test of sphericity demonstrated that for these results, sphericity could be assumed for light distribution, $\mathrm{X}^{2}(2)=1.38, \mathrm{p}=0.502$, level of MRSE, $\mathrm{X}^{2}(2)=3.353, \mathrm{p}=$ 0.187, and the interaction between level of MRSE and light distribution, $X^{2}(9)=10.598, p=$ 0.305. Within subjects effects then showed that subjective assessment of brightness was influenced by level of MRSE, F(2, 50) = 223.244, p $<0.001$, and also by light distribution, $\mathrm{F}(2,50)=11.520, \mathrm{p}<0.001$. There was also a significant interaction between level of MRSE and light distribution, $\mathrm{F}(4,100)=2.722, \mathrm{p}=0.002$. 
Post-hoc paired comparisons, using a Bonferroni correction, were made to examine which pairs of means differed. For light distribution, there was again a significant difference between direct and indirect scenes $(\mathrm{p}=0.001)$ and also between direct and mixed $(\mathrm{p}<0.001)$. No statistically significant difference could be concluded between the mixed and indirect scenes. For level of MRSE, there was a statistically significant difference between each of the pairs of means $(\mathrm{p}<0.001)$.

\subsection{Mean room surface exitance and mean horizontal illuminance}

Graphing the mean spatial brightness response of each light scene visually indicates the difference in relationship between MRSE and spatial brightness, compared with horizontal illuminance $\left(\mathrm{E}_{\mathrm{h})}\right.$ and spatial brightness (Figure 4 and 5). Applying a linear regression to MRSE and spatial brightness produces a strong relationship between the two items $\left(R^{2}=0.89\right)$. Within this experiment, horizontal illuminance was not explicitly controlled as an independent variable and in addition, participants viewed values of it within a small range, generally between 50 lux and 250 lux. However, applying a linear regression model to $\mathrm{E}_{\mathrm{h}}$ and spatial brightness serves as a pragmatic backward inference as to the relationship experienced between the two items. Considering the entire dataset as a whole, no predictable relationship could be found. Visually examining Figure 5 shows that three outlying points strongly influence the regression line. Applying a linear regression that excludes these points improves the relationship experienced $\left(R^{2}=0.46\right)$, but not to the level where it could be considered strong. 


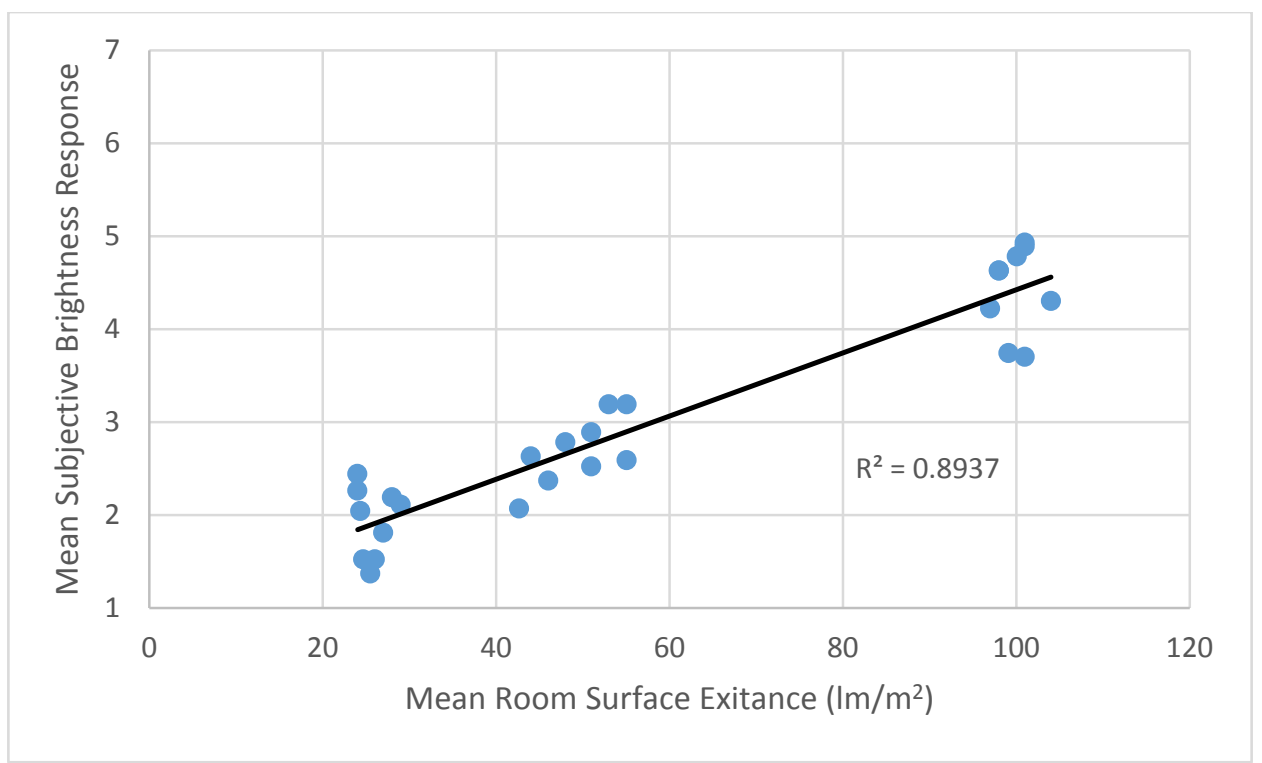

Figure 4. The mean spatial brightness rating plotted against the mean room surface exitance for each light scene presented.

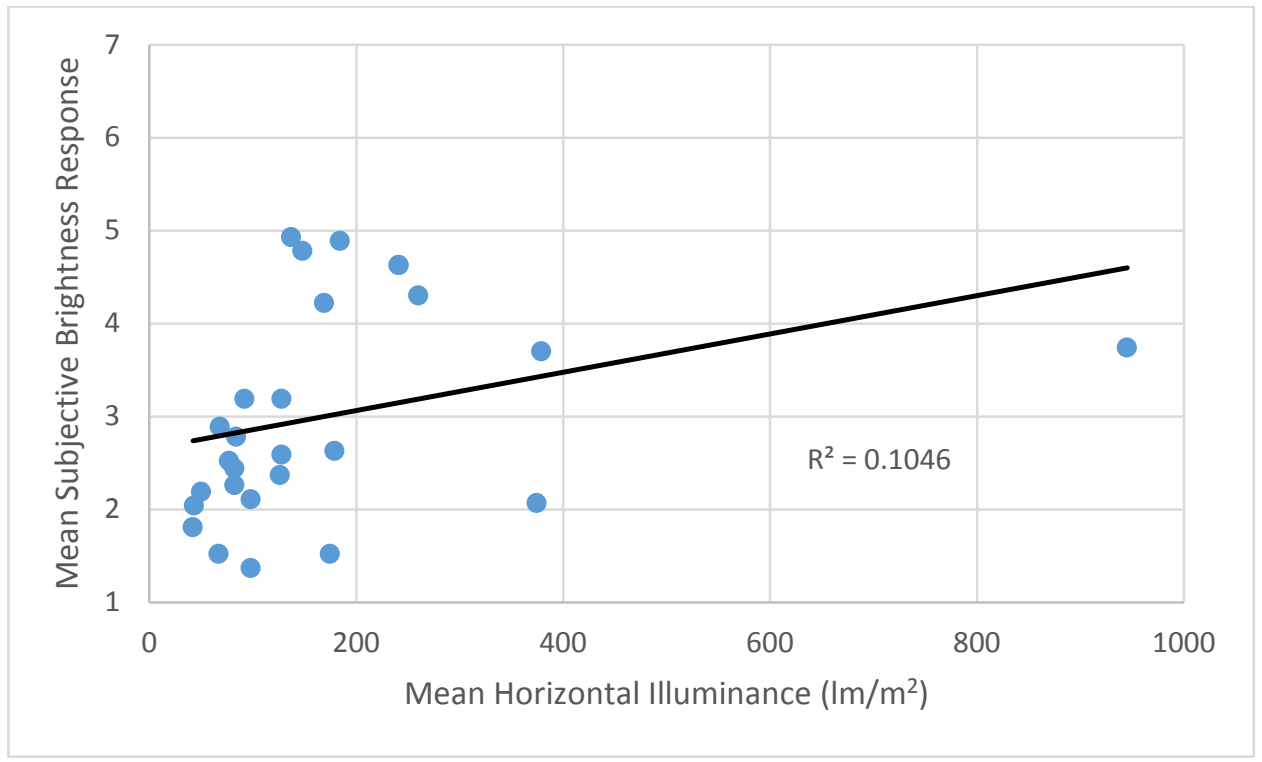

Figure 5. The mean spatial brightness rating plotted against the horizontal illuminance for each light scene presented.

\section{Discussion}

Analysis of the results has shown that regardless of light distribution or surface reflectance, in the light scenes presented, the level of MRSE had a significant impact on subjective assessment of spatial brightness. In addition, whilst participants were exposed to two 
independent variables during each sitting, MRSE and light distribution, analysis demonstrated that level of MRSE had a stronger impact on assessment of spatial brightness than light distribution.

The relationship between luminance and brightness has previously been shown to be logarithmic, ${ }^{36,37,38,39,40}$ but the upper levels of luminance used in these studies reached values far in excess of what the participants were exposed to in this experiment. Participants viewed scenes between $25 \mathrm{~lm} / \mathrm{m}^{2}$ and $100 \mathrm{~lm} / \mathrm{m}^{2}$, with the maximum recorded luminance being 86 $\mathrm{cd} / \mathrm{m}^{2}$. The results in this study demonstrated a strong linear relationship between MRSE and spatial brightness. Remembering that values one to seven were assigned to each response category from very dim to very bright, the relationship between spatial brightness $(B)$ and MRSE experienced in this study can be approximately given by:

$$
B=1+\frac{M R S E}{30}
$$

Again, it should be noted that the maximum value of MRSE used in this study was $100 \mathrm{~lm} / \mathrm{m}^{2}$. It is envisaged that as levels of MRSE increase above this value, ratings of brightness may plateau. Verifying and further understanding this relationship will be a focus for future work. From the linear regression analysis, and visually from Figures 4 and 5, it can be seen that for the light scenes used in this study, MRSE was a superior predictor of spatial brightness when compared with $E_{h}$. Logically, increasing or decreasing the luminance of the surfaces within a space will have an impact on how dim or bright it appears, but the illumination engineering metrics used to control this phenomena are not yet widely understood. Loe et al investigated subjective response to brightness using the average luminance and the luminance distribution standard deviation within a horizontal band $40^{\circ}$ wide. $^{27}$ The authors here did not record luminance values within the horizontal band $40^{\circ}$ wide, but did record luminance values on all 
booth surfaces. Using the premise that the mean luminance of the booth walls is approximately equivalent to that of the $40^{\circ}$ wide horizontal band, correlations can be drawn between mean wall luminance and MRSE $(r=0.95)$ and also between mean wall luminance and $\mathrm{E}_{\mathrm{h}}(r=0.69)$. This serves to highlight that if controlling luminance in the field of view is of importance, then for the scenes used in this study, even with a wide range of light distributions and surface reflectances, MRSE did a better job than $\mathrm{E}_{\mathrm{h}}$.

In two separate studies, Loe et $a l^{27,28}$ found that firstly, for a room to appear “light”, it needed to have an average luminance within the horizontal band $40^{\circ}$ wide of at least $30 \mathrm{~cd} / \mathrm{m}^{2}$ and secondly, that for a space to "begin to appear bright", luminance levels within the horizontal band $40^{\circ}$ wide need to be approximately $40 \mathrm{~cd} / \mathrm{m}^{2}$. The results found in this study show substantial agreement with these findings.

\section{Limitations}

The definition of brightness given to study participants should be considered. This was taken from previous work by Vrabel $e a^{35}$ and it informed participants to relate very bright to "the light in an outdoor sports area (when all the floodlights are on)” and relate very dim to the brightness "of an outdoor parking lot at night". Whilst defining the ends of the semantic scale has benefits, in this case, the chosen definition caused scale compression. None of the light scenes that participants viewed approached a brightness close to the level of an outdoor sports area, nor did they come close to the dimness of an outdoor parking lot at night. Defining these extremes may have ultimately suggested to participants that they should not choose towards the outer ends of the scale and results of this are evident in Figure 4, where few scenes were scored towards the upper end of the brightness scale. 
A range of surface reflectances was presented, but due to the nature of changing reflectance properties, participants experienced these in a fixed order, producing an associated order effect. As such, results across each of the surfaces reflectances could not be compared in an ideal manner.

While this research has examined a range of light distributions, it has not explored very extreme distributions. Truly non-uniform distributions were not investigated and it still remains unclear how participants will react to these.

Many past studies have investigated how the spectral power distribution of the lighting affects the perceived brightness of a space and this work is still on-going. The work presented in this paper did not vary spectral power distribution, with each of the sources used having a CCT of $4000 \mathrm{~K}$ and a CRI of 80 .

\section{Conclusion}

This paper presents a pilot study conducted as part of on-going research. It used a lighting booth to investigate the relationship between MRSE and spatial brightness under varying surface properties and light distributions, but with static source spectral power distributions. It then compared this relationship to the relationship between $\mathrm{E}_{\mathrm{h}}$ and spatial brightness under the same conditions. From the data collected and considering the limitations discussed, the key findings of this work have been:

- A simple linear relationship was found to exist between MRSE and spatial brightness.

- A broadly unpredictable relationship was found to exist between $E_{h}$ and spatial brightness.

These conclusions are drawn within the limitations discussed and in the knowledge that the experiment presented is a preliminary study. Further work is underway to continue investigating the topic. 
Funding 


\section{Reference list}

1. The Society of Light and Lighting. The SLL Code for Lighting. London: SLL, 2009.

2. Committee of European Standards. EN 12464-1:2011. Light and Lighting - Lighting of Workplaces. Part 1: Indoor Workplaces. London: CEN, 2011.

3. Boyce PR. Lighting quality for all? Proceedings of the SLL International Lighting Conference, Dublin, April 2013.

4. Cuttle C. Lighting by Design, 2nd edition, Oxford: Architectural Press, 2008.

5. Cuttle C. Towards the third stage of the lighting profession. Lighting Research and Technology, 2010; 42(1): 73-93.

6. Cuttle C. A new direction for general lighting practice. Lighting Research and Technology 2013; 45(1): 22-39.

7. Cuttle, C. Introduction to a novel perception-based approach to lighting design. Proceedings of the 4th Professional Lighting Design Convention, Copenhagen, 2013. 152-154.

8. Cuttle C. Lighting Design: A Perception-based Approach. Oxford: Routledge, 2015.

9. Fotios S, Atli D, Cheal C, Houser K, Logadóttir Á. Lamp spectrum and spatial brightness at photopic levels: A basis for developing a metric. Lighting Research and Technology 2013; 47(3): 80-102.

10. Loe D. Measuring the lit appearance of a space. Light and Lighting 1999; 11: 35-37.

11. Society of Light and Lighting. Code for Lighting. Oxford: Butterworth-Heinemann, 2002.

12. Bullough JD. Spectral sensitivity modelling and nighttime scene brightness perception. Leukos 2015; 11(1): 11-17.

13. Bullough JD, Radetsky L, Basenecker U. Influence of spectral power distribution on scene brightness at different light levels. Leukos 2014; 10(1): 3-9. 
14. Boyce PR. Investigations of the subjective balance between illuminance and lamp colour properties. Lighting Research and Technology 1977; 9: 11-24.

15. Fotios SA, Levermore GJ. The perception of electric light sources of different colour properties. Lighting Research and Technology 1997; 29: 161-171.

16. Hu X, Houser KW, Tiller DK. Higher colour temperature lamps may not appear brighter. Leukos 2006; 3: 69-81.

17. Alman DH. Errors of the standard photometric system when measuring the brightness of general illumination light sources. Journal of the Illuminating Engineering Society 1977; 6: 55-62.

18. Ju J, Chen D, Lin Y. Effects of correlated color temperature on spatial brightness perception. Color Research and Application 2012; 37: 450-454.

19. Harrington RE. Effect of color temperature on apparent brightness. Journal of the Optical Society of America 1954; 44: 113-116.

20. Levermore GJ. Perception of lighting and brightness from HID light sources. Lighting Research and Technology 1994; 26: 145-150.

21. Berman SM, Jewett DL, Fein G, Saika G, Ashford F. Photopic luminance does not always predict perceived room brightness. Lighting Research and Technology 1990; 22: 37-41.

22. Rea MS. New benefit metrics for more valuable lighting. Journal of Light and Visual Environment 2013, doi: IEIJ130000498.

23. Rea MS. Value Metrics for Better Lighting. Washington: SPIE Press, 2013.

24. Fotios S, Atli D, Cheal C, Hara N. Lamp spectrum and spatial brightness at photopic levels: Investigating prediction using S/P ratio and gamut area. Lighting Research and Technology 2014, doi:10.1177/1477153514546784.

25. Royer M, Houser KW. Spatial brightness perception of trichromatic stimuli. Leukos 2012; 9(2): 89-108. 
26. Rea MS, Mou X, Bullough JD. Scene brightness of illuminated interiors. Lighting Research and Technology. First published 21 April 2015.

doi:10.1177/1477153515581412.

27. Loe DL, Mansfield KP, Rowlands E. Appearance of the lit environment and its relevance in lighting design: experimental study. Lighting Research and Technology 1994; 26(3): 119-133.

28. Loe DL, Mansfield KP, Rowlands E. A step in quantifying the appearance of a lit scene. Lighting Research and Technology. 2000; 32(4): 213-222.

29. Venning B, Poulton K, Shaw K, Loe DL, Raynham P, Hoggett N. Cuttle's theory, the profession responds. Society of Light and Lighting Newsletter 2010; 3(1): 7-9.

30. Macrae I. Comment 1: A new direction for general lighting practice. Lighting Research and Technology, 2013; 45(1): 34-36.

31. Brandston HM. Comment 3: Towards the third stage of the lighting profession. Lighting Research and Technology, 2010; 42(1): 90-91.

32. Wilde, MB. Comment 2: A new direction for general lighting practice. Lighting Research and Technology, 2013; 45(1): 36-38.

33. Bedocs L. Comment 1: Towards the third stage of the lighting profession. Lighting Research and Technology, 2010; 42(1): 87-89.

34. Mansfield, KP. Comment 2: Towards the third stage of the lighting profession. Lighting Research and Technology 2010; 42(1): 89-90.

35. Vrabel PL, Bernecker CA, Mistrick RG. Visual performance and visual clarity under electric light sources: Part II - Visual clarity. Journal of Illuminating Engineering Society 1998; 27(1): 29-41.

36. Fechner GT. Elementeder Psychopysik. Munich: Breitkopf und Hartel, 1860.

37. Adams QE, Cobb PW. The effect of foveal vision on bright and dark surroundings. Journal of Experimental Psychology, 1992; 5: 39-45.

38. Stevens SS. To honour Fechner and repeal his law. Science, 1961; 3446: 80-86. 
39. Hurvich LM. Jameson D. Visual scaling. Handbook of Sensory Physiology, volume 7. Berlin: Springer, 1972.

40. Bodmann H-W, La Toison M. Predicted brightness - luminance phenomena. Lighting Research and Technology. 1994; 26(3): 135-143.

\section{Figure captions}

Figure Error! Main Document Only.. Front elevation of the lighting booth. Note the smaller measuring hatches and the larger central hatch for viewing. Measuring hatches, at similar spacing, were used on all sides of the booth, including the top and bottom surfaces.

Figure 2. Elevation and plan sections of the lighting booth. Note the position of lamps and the switching circuits as described in Section 2.

Figure 3. Graphical representation of each light scene programmed. Note that each sitting contained static surface reflectances, but varied levels of MRSE and light distribution.

Figure 4. The mean spatial brightness rating plotted against the mean room surface exitance for each light scene presented.

Figure 5. The mean spatial brightness rating plotted against the horizontal illuminance for each light scene presented. 
Table Error! Main Document Only.. Properties of the 27 lights scenes programmed. Also indicated is the mean subjective spatial brightness rating for each light scene.

\begin{tabular}{|c|c|c|c|c|c|c|c|c|c|c|}
\hline \multirow[b]{2}{*}{$\begin{array}{l}\text { Light } \\
\text { Scene }\end{array}$} & \multirow[b]{2}{*}{$\begin{array}{l}\text { Target } \\
\text { MRSE } \\
\left(\mathrm{lm} / \mathrm{m}^{2}\right)\end{array}$} & \multirow[b]{2}{*}{$\begin{array}{l}\text { Surface } \\
\text { Reflectance } \\
\text { (Ceiling/ } \\
\text { Wall/ Floor) }\end{array}$} & \multirow[b]{2}{*}{$\begin{array}{l}\text { Light } \\
\text { Distribution }\end{array}$} & \multirow[b]{2}{*}{$\begin{array}{l}\text { Recorded } \\
\text { MRSE } \\
\left(\mathrm{lm} / \mathrm{m}^{2}\right)\end{array}$} & \multirow[b]{2}{*}{$\begin{array}{l}\text { Recorded } \\
\text { Horizontal } \\
\text { Illuminance } \\
\left(\mathrm{lm} / \mathrm{m}^{2}\right)\end{array}$} & \multicolumn{4}{|c|}{ Mean Recorded Luminance $\left(\mathrm{cd} / \mathrm{m}^{2}\right)$} & \multirow[b]{2}{*}{$\begin{array}{l}\text { Mean Spatial } \\
\text { Brightness } \\
\text { Rating (SD) }\end{array}$} \\
\hline & & & & & & Floor & Ceiling & $\begin{array}{l}\text { Long } \\
\text { Wall }\end{array}$ & $\begin{array}{l}\text { Short } \\
\text { Wall }\end{array}$ & \\
\hline 1 & 25 & \multirow{9}{*}{$\begin{array}{l}\text { Sitting } 1 \\
88 / 83 / 27\end{array}$} & Indirect & 29 & 67 & 3 & 16 & 10 & 8 & $\begin{array}{c}2.08 \\
(0.92)\end{array}$ \\
\hline 2 & 25 & & Direct & 26 & 98 & 6 & 7 & 10 & 9 & $\begin{array}{c}1.54 \\
(0.57)\end{array}$ \\
\hline 3 & 25 & & Mixed & 28 & 50 & 4 & 12 & 10 & 9 & $\begin{array}{c}2.19 \\
(0.68) \\
\end{array}$ \\
\hline 4 & 50 & & Indirect & 51 & 68 & 5 & 28 & 17 & 15 & $\begin{array}{c}2.96 \\
(1.32)\end{array}$ \\
\hline 5 & 50 & & Direct & 46 & 126 & 11 & 13 & 16 & 16 & $\begin{array}{c}2.38 \\
(0.74)\end{array}$ \\
\hline 6 & 50 & & Mixed & 53 & 92 & 8 & 23 & 19 & 16 & $\begin{array}{c}3.19 \\
(0.83)\end{array}$ \\
\hline 7 & 100 & & Indirect & 101 & 137 & 9 & 56 & 34 & 30 & $\begin{array}{c}4.96 \\
(1.16)\end{array}$ \\
\hline 8 & 100 & & Direct & 104 & 260 & 22 & 28 & 40 & 34 & $\begin{array}{c}4.31 \\
(1.29)\end{array}$ \\
\hline 9 & 100 & & Mixed & 101 & 184 & 16 & 42 & 36 & 31 & $\begin{array}{c}4.92 \\
(0.92)\end{array}$ \\
\hline 10 & 25 & \multirow{9}{*}{$\begin{array}{l}\text { Sitting } 2 \\
73 / 64 / 27\end{array}$} & Indirect & 27 & 42 & 3 & 19 & 9 & 7 & $\begin{array}{c}1.85 \\
(0.77)\end{array}$ \\
\hline 11 & 25 & & Direct & 26 & 98 & 8 & 7 & 10 & 8 & $\begin{array}{c}1.38 \\
(0.56)\end{array}$ \\
\hline 12 & 25 & & Mixed & 24 & 82 & 4 & 13 & 9 & 7 & $\begin{array}{c}2.27 \\
(0.65) \\
\end{array}$ \\
\hline 13 & 50 & & Indirect & 51 & 77 & 5 & 36 & 16 & 13 & $\begin{array}{c}2.58 \\
(0.84)\end{array}$ \\
\hline 14 & 50 & & Direct & 44 & 179 & 15 & 12 & 15 & 15 & $\begin{array}{c}2.65 \\
(0.68)\end{array}$ \\
\hline 15 & 50 & & Mixed & 55 & 128 & 10 & 28 & 19 & 15 & $\begin{array}{c}2.62 \\
(0.62) \\
\end{array}$ \\
\hline 16 & 100 & & Indirect & 100 & 148 & 9 & 70 & 32 & 24 & $\begin{array}{c}4.81 \\
(1.14)\end{array}$ \\
\hline 17 & 100 & & Direct & 101 & 379 & 29 & 25 & 39 & 33 & $3.73(1.16)$ \\
\hline 18 & 100 & & Mixed & 98 & 241 & 19 & 46 & 33 & 27 & $\begin{array}{c}4.65 \\
(1.04)\end{array}$ \\
\hline 19 & 25 & $\begin{array}{l}\text { Sitting } 3 \\
48 / 44 / 13\end{array}$ & Indirect & 24 & 43 & 2 & 21 & 7 & 5 & $\begin{array}{c}1.58 \\
(0.78)\end{array}$ \\
\hline
\end{tabular}




\begin{tabular}{|c|c|c|c|c|c|c|c|c|c|}
\hline 20 & 25 & Direct & 25 & 175 & 9 & 5 & 9 & 8 & $\begin{array}{c}1.27 \\
(0.52)\end{array}$ \\
\hline 21 & 25 & Mixed & 24 & 82 & 4 & 13 & 9 & 7 & $\begin{array}{c}2.15 \\
(0.57)\end{array}$ \\
\hline 22 & 50 & Indirect & 48 & 84 & 3 & 43 & 14 & 9 & $\begin{array}{c}2.42 \\
(0.99)\end{array}$ \\
\hline 23 & 50 & Direct & 43 & 374 & 17 & 10 & 14 & 15 & $\begin{array}{c}1.96 \\
(0.72)\end{array}$ \\
\hline 24 & 50 & Mixed & 55 & 128 & 10 & 28 & 19 & 15 & $\begin{array}{c}2.54 \\
(0.96)\end{array}$ \\
\hline 25 & 100 & Indirect & 97 & 169 & 7 & 86 & 28 & 18 & $\begin{array}{c}5.08 \\
(1.00)\end{array}$ \\
\hline 26 & 100 & Direct & 99 & 945 & 50 & 29 & 45 & 45 & $\begin{array}{c}4.08 \\
(0.94)\end{array}$ \\
\hline 27 & 100 & Mixed & 98 & 241 & 19 & 46 & 33 & 27 & $\begin{array}{c}4.38 \\
(1.09)\end{array}$ \\
\hline
\end{tabular}

